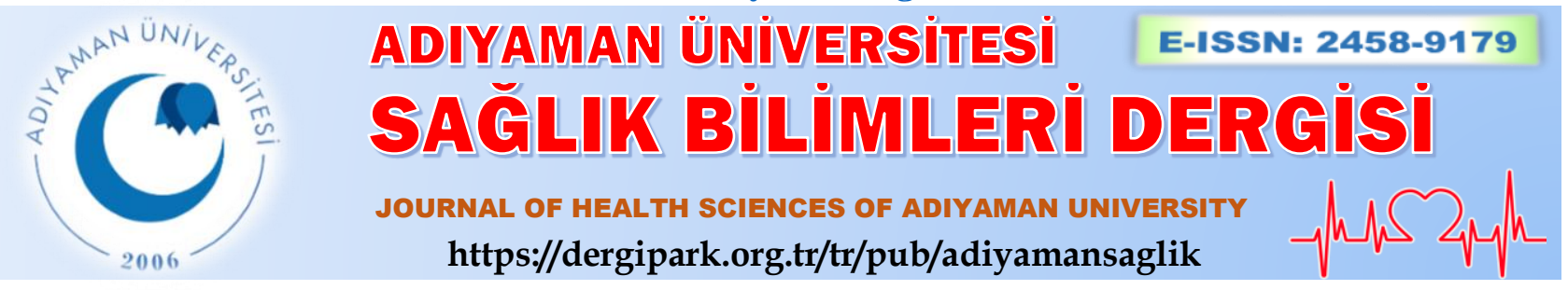

Özgün Araştırma/Research Article

\title{
Gebelerin oral glukoz tolerans testi yaptırmalarını etkileyen faktörlerin incelenmesi
}

\section{Investigation of factors affecting the approach of pregnant women to oral glucose tolerance test}

Zekiye TURAN 1 (D) Eylem TOKER ${ }^{2}(\mathrm{D}$

${ }^{1}$ Sakarya Üniversitesi, Sağlık Bilimleri Fakültesi, Hemşirelik Bölümü, 54050, Sakarya-Türkiye

${ }^{2}$ Kahramanmaraş Sütçü İmam Üniversitesi, Sağlık Bilimleri Fakültesi, Ebelik Bölümü, 46050, Kahramanmaraş-Türkiye

Atıf gösterme/Cite this article as: Turan Z, Toker E. Gebelerin oral glukoz tolerans testi yaptırmalarını etkileyen faktörlerin incelenmesi. ADYÜ Să̆llk Bilimleri Derg. 2020;6(2):174-181. doi:10.30569.adiyamansaglik.726335

Öz

Amaç: $\mathrm{Bu}$ çalışmanın amacı, gebelerin oral glukoz tolerans testi yaptırmalarını etkileyen faktörlerin belirlenmesidir.

Gereç ve Yöntem: Çalışma, tanımlayıcı tipte kesitsel bir araştırmadır. Araştırmanın örneklemini, araştırmaya katılmayı kabul eden 148'i oral glukoz tolerans testi (OGTT) yaptıran, 149'u OGTT yaptırmayan toplam 297 gebe oluşturmuştur.

Bulgular: Gebelerin sosyo-demografik, sağlik ve obstetrik özelliklerinin OGTT yaptırma üzerine etki etmediği belirlenmiştir. OGTT yaptırmayan gebelerin \%56,3'ünün testin gerekli olmadığını düşündükleri, $\% 21,5$ 'inin testin kendilerine ve bebeklerine zararlı olduğunu düşündükleri ve \%17,4'ünün de doktorları önermediği için yaptırmadıkları saptanmıştır.

Sonuç: $\mathrm{Bu}$ çalışma kapsamında, gebelerin sosyodemografik, sağlık ve obstetrik özelliklerinin OGTT yaptırma davranışı üzerine etki etmediği; testin gerekli olmadığını düşünme, kendilerine ve bebeklerine zararlı olacağı endişesi ve doktorlarının önermemesi sebepleri ile testi yaptırmadıkları saptanmıştır.

Anahtar Kelimeler: OGTT; Gebelik; Prenatal testler; Ebe; Hemşire.

\begin{abstract}
Aim: The aim of this study is to determine the factors affecting the approach of pregnant women to oral glucose tolerance test.

Materials and Methods: The research is a descriptive cross-sectional study. The sample consisted of 297 pregnant, which of 148, who had oral glucose tolerance test (OGTT) and 149 didn't have OGTT.

Results: It was determined that socio-demographic, health and obstetric features of pregnant women didn't affect attitude OGTT. It was found that $56.3 \%$ of the pregnant women who didn't have OGTT thought that the test wasn't necessary, $21.5 \%$ thought that the test was harmful for them and their babies and $17.4 \%$ stated that doctors didn't recommend.

Conclusion: It was determined that sociodemographic, health and obstetric features of pregnant women didn't affect the OGTT attitude; they thought that the test wasn't necessary, and that they wouldn't harm the patients and their babies, and stated that doctors didn't recommend.
\end{abstract}

Keywords: OGTT; Pregnancy; Prenatal tests; Midwife; Nurse.

Yazışma Adresi/Address for Correspondence: Zekiye TURAN, Sakarya Üniversitesi, Sağlık Bilimleri Fakültesi, Esentepe Kampüsü, 54050, Balıkesir-Türkiye, E-mail: zekiyeturan@sakarya.edu.tr

Geliş Tarihi/Received:24.04.2020 Kabul Tarihi/Accepted:05.05.2020

Yayım Tarihi/Published online:30.08.2020

Bu eser, Creative Commons Atıf-GayriTicari 4.0 Uluslararası Lisansı ile lisanslanmıștır. Telif Hakkı @ 2020 Adıyaman Üniversitesi Rektörlüğü 


\section{Giriş}

Gebelik ile birlikte ortaya çıkan gestasyonel diyabet (GDM), gebeliği zorlaştıran en yaygın endokrinolojik problemlerden biridir. ${ }^{1-3}$ Uluslararası Diyabet Federasyonunun (International Diabetes Federation-IDF) verilerine göre, canl1 doğumların $\% 16,2$ 'sinde gebelikte hiperglisemi geliştiği ve bunların yaklaşık olarak \%85,1'inin gestasyonel diyabete bağl1 hiperglisemi olduğu bildirilmiştir. ${ }^{4}$ Amerikan Diyabet Derneği (American Diabetes Association-ADA) tüm dünyada obezite oranının artışı ile birlikte gebelikte diyabet görülme prevelansının da artığını vurgulamaktadır. ${ }^{5} \quad$ Ülkemizde farklı zamanlarda ve farklı yerlerde yapılan çalışmalarda GDM prevalansının \%2,6 ile $\% 24,8$ arasında değiştiği görülmektedir. ${ }^{6-8}$

GDM'nin beraberinde anne ve fetus için birçok olumsuz sonuç doğurduğu bilinmektedir. GDM ile pre-eklampsi, makrozomi, maternal doğum travması, yenidoğanda doğum travması, artmış operatif doğum ve sezaryen doğum riski arasında önemli bir ilişki olduğu belirtilmiştir., ${ }^{9,10}$ Yenidoğan döneminde ise respiratuvar distres, hipoglisemi, hiperbilirubinemi, polisitemi, hipokalsemi-hipomagnezemi komplikasyonlar ortaya çıkabildiği gösterilmiştir. ${ }^{11,12}$

Gebelikte diyabet taramasının amac1, asemptomatik bireyleri tanımlamaktır. Günümüzde birçok ulusal ve uluslararası sağlık kurum ve örgütleri gebelikte GDM taramasinda oral glukoz tolerans testini (OGTT) önermektedir. ${ }^{13-17}$

Gebelik döneminde GDM ile ilgili olarak zamanında ve etkili bir tedavi ile preeklampsi ve makrozomi gibi maternal ve neonatal olumsuzluk gelișme riski azaltılabilir. ${ }^{18,19}$ GDM ile ilgili farkındalık oluşturma, tanı ve tarama testleri ile erken tanı koyma, olumsuz sonuçların riskini azaltmada anahtar faktörlerdir. ${ }^{18}$ Literatürde yapılan bir çalışmada antenatal dönemde yapilan testler arasında oral glukoz tolerans testi'nin (OGTT) \%22,7 oranında yapıldı belirlenmiştir. ${ }^{20}$ Bunun nedeni olarak gebe kadınlarda glikoz tolerans testine karşı negatif bir tutum olduğu belirtilmiştir. Kaynağı internet ve televizyon gibi kitle iletişim araçları olan bu negatif tutum, tanı almamış vaka sayısında artışa ve dolayısıyla gebelik, doğum ve doğum sonu komplikasyon sıklığında artışa neden olabilecek potansiyel bir tehlike oluşturmaktadır. ${ }^{21}$

$\mathrm{Bu}$ çalışmanın amacı, gebelerin oral glukoz tolerans testi yaptırmalarını etkileyen faktörlerin belirlenmesidir.

\section{Gereç ve Yöntem}

\section{Araştırmanın tipi}

Araştırma tanımlayıcı tipte kesitsel bir araştırmadır.

\section{Araştırmanın evreni ve örneklemi}

Araştırmanın evrenini, Sağlık Bakanlığına bağlı bir kamu hastanesinin Doğum ve Kadın Hastalıkları Polikliniklerine başvuru yapan 28 haftadan büyük gebeliğe sahip olan tüm gebeler oluşturmaktadır. Araştırmanın örneklemini ise, Ekim 2019- Şubat 2020 tarihleri arasında örneklem dahil olma kriterlerine uyan ve araştırmaya katılmayı kabul eden 148'i OGTT yaptıran, 149'u OGTT yaptırmayan toplam 297 gebe oluşturmuştur.

\section{Örneklem dahil olma kriterleri:}

Araştırmanın örneklemine; araştırmaya katılmayı kabul eden, 19 yaş ve üzerinde olan, 28 haftadan büyük gebeliğe sahip olan, iletişim güçlüğü veya problemi olmayan ve psikiyatrik hastalığı olmayan gebeler dahil edilmiştir.

\section{Örneklem dışlanma kriterleri:}

Örneklem dahil olma kriterleri dışında kalan gebeler örnekleme dahil edilmemiştir.

\section{Veri toplama aracı}

Veri toplama aracı olarak, araştırmacılar tarafından literatür taranarak hazırlanan anket formu kullanılmıştır. ${ }^{18,21-23}$ Anket formu 3 bölümden oluşmuştur; ilk bölümde sosyodemografik bilgileri sorgulayan 7 soru, ikinci bölümde sağlik ve obstetrik öyküsünün sorgulandığı 12 soru ve üçüncü bölümde şu anki gebelikle ilgili bilgileri ve OGTT yaptırma durumlarını sorgulayan 10 soru olmak üzere toplam 29 sorudan oluşmuştur. 


\section{Veri analizi}

Veriler normal dağılım göstermemektedir. $\mathrm{Bu}$ nedenle kantitatif veriler tablolarda medyan (max-min) değerler şeklinde belirtildi. Kategorik veriler ise n (sayı) ve yüzdelerle (\%) verildi. Bağımsız grupların gruplar arası karşılaştırılmasında Mann Whitney $U$ testleri kullanıldı. Kategorik verilerin karşılaştırılmasında ise Pearson chisquare ve Fisher Exact testleri kullanıld. Veriler $\% 95$ güven düzeyinde incelendi, $p$ değeri 0,05 'ten küçük ise anlamlı kabul edildi.

\section{Araştırmanın etik boyutu}

Araştırmanın yapılabilmesi için kurum izni alınarak etik kurul onayı alınmıştır (Tarih: 10.10.2019; No: 71522473/050.01.04/85). Ayrıca çalışmanın yürütülmesinde Helsinki Bildirgesi ilkelerine uyulmuştur.

\section{Araştırmanın sınırlııkları}

Çalışmaya dahil edilen gebelerin çalışma sonrası gebelik ve doğum sonuçlarının takip edilmemiş olması, ayrıca çalışmanın tek merkezde yapılması araştırmamızın sınırlılıkları içindedir.

\section{Bulgular}

Araştırmaya katılan gebelerin yaş ortalamasi 29 (min 19-max 43) olup, \%69,7'si ilçe merkezinde ikamet eden, $\% 48,8$ i ilköğretim mezunu, \%79,1'i herhangi bir yerde çalışmayan (ev hanımı), \%66,7'si orta düzey gelire sahip gebelerden oluşmaktadır. Gebelerin sosyo-demografik bilgileri ile OGTT yaptırma durumları karşılaştırıldığında; sosyo-demografik özellikler açısından OGTT yaptıran ve OGTT yaptırmayan gruplar arasinda istatistiksel olarak anlamlı bir fark olmadı̆̆ $(p>0,05)$ saptanmıştır (Tablo 1).

Tablo 1. Gebelerin sosyo-demografik özelliklerine göre OGTT yaptırma durumları

\begin{tabular}{|c|c|c|c|c|c|c|c|}
\hline \multirow{4}{*}{$\begin{array}{l}\text { SOSYO- } \\
\text { DEMOGRAFIK } \\
\text { ÖZELLIKLER } \\
\text { Yaş }\end{array}$} & \multirow{2}{*}{\multicolumn{2}{|c|}{$\begin{array}{l}\begin{array}{l}\text { OGTT YAPTIRAN } \\
(\mathrm{n}=148)\end{array} \\
\text { Ortanca (min- max) } \\
\end{array}$}} & \multirow{2}{*}{\multicolumn{2}{|c|}{$\begin{array}{l}\text { OGTT } \\
\text { YAPTIRMAYAN } \\
(n=149) \\
\text { Ortanca (min- max) }\end{array}$}} & \multicolumn{2}{|c|}{$\begin{array}{l}\text { TOPLAM } \\
(n=297)\end{array}$} & \multirow{4}{*}{$\begin{array}{l}\text { Test ve } \boldsymbol{p} \text { değeri } \\
\begin{array}{l}\mathrm{Z}=-0,185 \\
p=0,853\end{array}\end{array}$} \\
\hline & & & & & Orta & $a(\min -\max )$ & \\
\hline & \multicolumn{2}{|c|}{$28,50(19-43)$} & \multicolumn{2}{|c|}{$29,00(19-43)$} & \multicolumn{2}{|c|}{$29,00(19-43)$} & \\
\hline & Sayı & $\%$ & Sayı & $\%$ & Sayı & $\%$ & \\
\hline $\begin{array}{l}\text { Yaşadığı yer } \\
\text { Köy } \\
\text { İlçe } \\
\text { İl merkezi }\end{array}$ & $\begin{array}{l}17 \\
109 \\
22 \\
\end{array}$ & $\begin{array}{l}11,5 \\
73,6 \\
14,9\end{array}$ & $\begin{array}{l}18 \\
98 \\
33 \\
\end{array}$ & $\begin{array}{l}12,1 \\
65,8 \\
22,1 \\
\end{array}$ & $\begin{array}{l}35 \\
207 \\
55 \\
\end{array}$ & $\begin{array}{l}11,8 \\
69,7 \\
18,5 \\
\end{array}$ & $\begin{array}{l}X^{2}=2,810 \\
p=0,245\end{array}$ \\
\hline $\begin{array}{l}\text { Ĕgitim } \\
\text { İlköğretim } \\
\text { Lise } \\
\text { Üniversite }\end{array}$ & $\begin{array}{l}68 \\
46 \\
34\end{array}$ & $\begin{array}{l}45,9 \\
31,1 \\
23,0\end{array}$ & $\begin{array}{l}77 \\
46 \\
26\end{array}$ & $\begin{array}{l}51,7 \\
30,9 \\
17,4\end{array}$ & $\begin{array}{l}145 \\
92 \\
60\end{array}$ & $\begin{array}{l}48,8 \\
31,0 \\
20,2\end{array}$ & $\begin{array}{l}\mathrm{X}^{2}=1,622 \\
p=0,444\end{array}$ \\
\hline $\begin{array}{l}\text { Çalışma durumu } \\
\text { Ev hanımı } \\
\text { Çalışan }\end{array}$ & $\begin{array}{l}115 \\
33\end{array}$ & $\begin{array}{l}77,7 \\
22,3 \\
\end{array}$ & $\begin{array}{l}120 \\
29\end{array}$ & $\begin{array}{l}80,5 \\
19,5 \\
\end{array}$ & $\begin{array}{l}235 \\
62\end{array}$ & $\begin{array}{l}79,1 \\
20,9 \\
\end{array}$ & $\begin{array}{l}X^{2}=0,361 \\
p=0,548\end{array}$ \\
\hline $\begin{array}{l}\text { Ekonomik durum } \\
\text { Kötü } \\
\text { Orta } \\
\text { İyi }\end{array}$ & $\begin{array}{l}44 \\
102 \\
2\end{array}$ & $\begin{array}{l}29,7 \\
68,9 \\
1,4\end{array}$ & $\begin{array}{l}48 \\
96 \\
7\end{array}$ & $\begin{array}{l}32,2 \\
64,4 \\
3,4\end{array}$ & $\begin{array}{l}92 \\
198 \\
7\end{array}$ & $\begin{array}{l}31,0 \\
66,7 \\
2,4\end{array}$ & $\begin{array}{l}X^{2}=1,638 \\
p=0,441\end{array}$ \\
\hline
\end{tabular}

Gebelerin sağlık durumu özelliklerine göre OGTT yaptırma durumları karşılaştırıldığında, OGTT yaptıran ve OGTT yaptırmayan gruplar arasında istatistiksel olarak anlamlı bir fark saptanmamıştır $(p>0,05)$ (Tablo 2).

Gebelerin obstetrik incelendiğinde; \%30'unun ilk gebeliği olduğu, \%13,9'unun diyabet tanısının bulunduğu, ortalama gebelik haftasının 36 hafta (min 28-max 41) olduğu, \%65,1'inin şimdiki gebeliği istediği, \%75,8'inin doğum öncesi bakım (DÖB) almadığını beyan ettiği, DÖB alanların ise \%55 inin yeterli sayıda bakım aldığı ve \%49,3'ünün bu DÖB bakımı ebeden aldığ 1 (Tablo 3) belirlenmiştir. 
Tablo 2. Gebelerin sağlık özelliklerine göre OGTT yaptırma durumları.

\begin{tabular}{|c|c|c|c|c|c|c|c|}
\hline \multirow{2}{*}{$\begin{array}{l}\text { GENEL SAĞLIK } \\
\text { ÖZELLİKLERİ }\end{array}$} & \multicolumn{2}{|c|}{$\begin{array}{l}\text { OGTT } \\
\text { YAPTIRAN } \\
(\mathrm{n}=148)\end{array}$} & \multicolumn{2}{|c|}{$\begin{array}{l}\text { OGTT } \\
\text { YAPTIRMAYAN } \\
(n=149)\end{array}$} & \multicolumn{2}{|c|}{$\begin{array}{l}\text { TOPLAM } \\
(n=297)\end{array}$} & \multirow[t]{2}{*}{ Test ve $p$ değeri } \\
\hline & $\%$ & Sayı & $\%$ & Sayı & $\%$ & Sayı & \\
\hline \multicolumn{8}{|l|}{ Kronik Hastalık } \\
\hline Var & 18 & 12,2 & 19 & 12,8 & 37 & 12,5 & \multirow{2}{*}{$\begin{array}{l}X^{2}=0,024 \\
p=0,878\end{array}$} \\
\hline Yok & 130 & 87,8 & 130 & 87,2 & 260 & 87,5 & \\
\hline \multicolumn{8}{|l|}{ Kronik Hastalıklar** } \\
\hline Diyabet & 2 & 11,1 & 3 & 15,8 & 5 & 13,5 & \multirow{4}{*}{$\begin{array}{l}\mathrm{X}^{2}=1,185 \\
p=0,857^{*}\end{array}$} \\
\hline Hipertansiyon & 4 & 22,2 & 2 & 10,5 & 6 & 16,2 & \\
\hline Kalp Hastalığ & 3 & 16,7 & 3 & 15,8 & 6 & 16,2 & \\
\hline Diğer & 9 & 50,0 & 11 & 57,9 & 19 & 54,1 & \\
\hline \multicolumn{8}{|l|}{ Ailede Diyabet Varlığı } \\
\hline Var & 64 & 43,2 & 52 & 34,9 & 116 & 39,1 & \multirow{2}{*}{$\begin{array}{l}X^{2}=2,172 \\
p=0,141\end{array}$} \\
\hline Yok & 84 & 56,8 & 97 & 65,1 & 181 & 60,9 & \\
\hline \multicolumn{8}{|c|}{ Ailede Diyabet öyküsü varlığı*** } \\
\hline Birinci derece akrabada & 52 & 81,2 & 41 & 78,8 & 93 & 80,2 & \multirow{2}{*}{$\begin{array}{l}X^{2}=0,104 \\
p=0,747\end{array}$} \\
\hline İkinci Derece akrabada & 12 & 18,8 & 11 & 21,2 & 23 & 19,8 & \\
\hline
\end{tabular}

* Fisher exact test

** Kronik Hastalığı olanların verdiği cevaplar

*** Ailede diyabet öyküsü olanların verdiği cevaplar

Gebelerin obstetrik özelliklerine göre OGTT yaptırma durumları karşılaştırıldığında, OGTT yaptıran ve OGTT yaptırmayan gruplar arasında istatistiksel olarak anlamlı bir fark olmadığ $1(p>0,05)$ saptanmıştır (Tablo 3)

OGTT yaptırmayan gebelerin yaptırmama nedenleri incelendiğinde, \%56,3'ünün testin gerekli olmadığını düşündükleri, \%21,5'inin testin kendilerine ve bebeklerine zararlı olduğunu düşündükleri için ve $\% 17,4$ 'ünün de doktorları önermediği için testi yaptırmadıklarını belirttikleri saptanmıştır (Tablo 4).

\section{Tartışma}

GDM'nin erken tespiti, maternal ve fetal komplikasyonların önlenmesi ve uygun bir şekilde tedavisi için oldukça önemlidir. Ancak gebe kadınlarda, glukoz tolerans testine karşı yaygın bir negatif tutum mevcuttur. $\mathrm{Bu}$ tutum tanı almamış vaka sayısında ve komplikasyon sıklığında artışa neden olabilecek potansiyel bir tehlike oluşturmaktadır. ${ }^{21}$

Literatürde yapılan çalışmalarda OGTT yaptırmaya etki eden sosyo-demografik özellikler incelendiğinde; kadınların yaşının, mesleğinin, eğitim ve gelir düzeylerinin etkili olmadığ1 gözlenmiştir. ${ }^{12,21-23}$ Yapılan bir çalışmada yaşanılan yer açısından köy ve kasabada oturanların şehirde oturanlara göre anlamlı bir şekilde daha fazla oranda OGTT yaptırmak istediği bulunmuştur. ${ }^{12}$ Literatürün aksine çalışmamızda kent merkezinde yaşayan gebelerde OGTT yaptırma oranları düşük tespit edilmiştir (Tablo 1). Çalışmada gebelerin OGTT yaptırmalarına sosyodemografik özelliklerinin etki etmediği gözlenmiştir.

Öte yandan literatür incelendiğinde kadınlarda GDM görülme riskini artıran faktörlerden, iki gebelik arasında geçen süre, multiparite ve yaş gibi faktörler göz önüne alındığında daha önce gestasyonel diyabet öyküsü olan ve gebelik öncesinde glukoz intoleransı olan kadınlarda teste karşı pozitif tutum siklığının daha yüksek olduğu bildirilmiştir. ${ }^{21,24}$ Yine Kutlu ve ark. ${ }^{25}$ yaptığ çalışmada doğum sayısı arttıkça gebelerin tarama testleri farkındalıklarının arttığını bildirmiştir. Oysaki çalışmada gebelerin sağlık durumları, kendi ve ailelerindeki diyabet varlığının, önceki ve şimdiki obstetrik öykülerinin ve almış oldukları doğum öncesi bakım özellikleri karşılaştırıldığında OGTT yaptırma üzerine bu faktörlerin anlaml oranda etki etmediği saptanmıştır (Tablo 3). $\mathrm{Bu}$ sonuç kadınların OGTT yaptırmamalarını etkileyen başka faktörlerin olduğu sonucunu bize düşündürmektedir. Gruplar arasında fark olmasa da OGTT yaptıran ve OGTT yaptırmayan gebelerin büyük çoğunluğunun doğum öncesi bakım hizmeti almadığını beyan etmeleri (Tablo 3), doğum öncesi bakım hizmeti kavramını farklı algilıyor olmalarından kaynaklanabileceği 
düşünülmektedir. Doğum öncesi bakım beklentiler ile ilgili farklı araştırmalar hizmetinin algilanması ve bu hizmetten yapılması bu açıdan önemlidir.

Tablo 3. Gebelerin obstetrik özelliklerine göre OGTT yaptırma durumları

\begin{tabular}{|c|c|c|c|c|c|c|c|c|}
\hline \multirow{2}{*}{$\begin{array}{l}\text { OBSTETRİK } \\
\text { ÖZELLİKLER }\end{array}$} & \multicolumn{2}{|c|}{$\begin{array}{l}\text { OGTT yaptiran } \\
(n=148)\end{array}$} & \multicolumn{2}{|c|}{$\begin{array}{l}\text { OGTT } \\
\text { Yaptırmayan } \\
(n=149)\end{array}$} & \multicolumn{2}{|c|}{$\begin{array}{l}\text { TOPLAM } \\
(\mathbf{n}=297)\end{array}$} & \multirow[t]{2}{*}{$\begin{array}{l}\text { Test ve } \\
\text { değeri }\end{array}$} & \multirow[t]{2}{*}{$p$} \\
\hline & Ort & n-max) & Ort & in-max) & Ort & in-max) & & \\
\hline Gebelik Haftası & 36( & & 36( & & 36 & 41) & $\begin{array}{l}Z=-1,710 \\
p=0,087\end{array}$ & \\
\hline Gebelikte Alınan Kilo & 10( & & 11( & 30) & 11( & 49) & $\begin{array}{l}\mathrm{Z}=-1,929 \\
p=0,054\end{array}$ & \\
\hline & $\%$ & Sayı & $\%$ & Sayı & $\%$ & Sayı & & \\
\hline $\begin{array}{l}\text { Gravida } \\
\text { Primigravid } \\
\text { Multigravid }\end{array}$ & $\begin{array}{l}47 \\
101\end{array}$ & $\begin{array}{l}31,8 \\
68,2\end{array}$ & $\begin{array}{l}42 \\
107\end{array}$ & $\begin{array}{l}28,2 \\
71,8\end{array}$ & $\begin{array}{l}89 \\
208\end{array}$ & $\begin{array}{l}30,0 \\
70,0\end{array}$ & $\begin{array}{l}X^{2}=0,451 \\
p=0,502\end{array}$ & \\
\hline $\begin{array}{l}\text { Planlı Gebelik } \\
\text { Evet } \\
\text { Hayır }\end{array}$ & $\begin{array}{l}103 \\
45\end{array}$ & $\begin{array}{l}69,6 \\
30,4\end{array}$ & $\begin{array}{l}89 \\
58\end{array}$ & $\begin{array}{l}60,5 \\
39,5\end{array}$ & $\begin{array}{l}192 \\
103\end{array}$ & $\begin{array}{l}65,1 \\
34,9\end{array}$ & $\begin{array}{l}X^{2}=2,658 \\
p=0,103\end{array}$ & \\
\hline $\begin{array}{l}\text { Doğum Öncesi } \text { Bakım } \\
\text { Hizmeti Alma } \\
\text { Evet } \\
\text { Hayır }\end{array}$ & $\begin{array}{l}37 \\
111\end{array}$ & $\begin{array}{l}25,0 \\
75,0\end{array}$ & $\begin{array}{l}37 \\
112\end{array}$ & $\begin{array}{l}24,8 \\
75,2\end{array}$ & $\begin{array}{l}74 \\
223\end{array}$ & $\begin{array}{l}24,9 \\
75,1\end{array}$ & $\begin{array}{l}X^{2}=0,001 \\
p=0,973\end{array}$ & \\
\hline $\begin{array}{l}\text { Doğum Öncesi Bakım } \\
\text { Hizmetini Aldığı Kişi } \\
\text { Doktor } \\
\text { Ebe } \\
\text { Hemşire } \\
\text { Doktor ve ebe }\end{array}$ & $\begin{array}{l}3 \\
16 \\
3 \\
15\end{array}$ & $\begin{array}{l}8,1 \\
44,2 \\
8,1 \\
40,6\end{array}$ & $\begin{array}{l}3 \\
20 \\
6 \\
8\end{array}$ & $\begin{array}{l}8,1 \\
54,1 \\
16,2 \\
21,6\end{array}$ & $\begin{array}{l}6 \\
36 \\
9 \\
23\end{array}$ & $\begin{array}{l}8,1 \\
48,6 \\
12,2 \\
31,1\end{array}$ & $\begin{array}{l}X^{2}=3,575 \\
p=0,311 *\end{array}$ & \\
\hline
\end{tabular}

\section{Doğum Öncesi Bakım \\ Alma Sayısı}

$<4$

$>4$

$15 \quad 40,5 \quad 16 \quad 43,2$

56,8

31

41,9

$\mathrm{X}^{2}=0,056$

$22 \quad 59,5$

21

Gebelikte Problem Varlığı

\begin{tabular}{|c|c|c|c|c|c|c|c|}
\hline $\begin{array}{l}\text { Evet } \\
\text { Hayır }\end{array}$ & $\begin{array}{l}64 \\
81\end{array}$ & $\begin{array}{l}44,1 \\
55,9\end{array}$ & $\begin{array}{l}63 \\
82\end{array}$ & $\begin{array}{l}43,4 \\
56,6\end{array}$ & $\begin{array}{l}127 \\
163\end{array}$ & $\begin{array}{l}43,8 \\
56,2\end{array}$ & $\begin{array}{l}X^{2}=0,014 \\
p=0,906\end{array}$ \\
\hline \multicolumn{8}{|c|}{ Geçmiş Obstetrik Bilgileri*** } \\
\hline \multicolumn{8}{|c|}{ Önceki Doğum Şekli**** } \\
\hline Sezaryen & 56 & 56,0 & 55 & 53,9 & 111 & 55,0 & $X^{2}=0,088$ \\
\hline Normal Doğum & 44 & 44,0 & 47 & 46,1 & 91 & 45,0 & $p=0,767$ \\
\hline \multicolumn{8}{|c|}{$\begin{array}{lll}\text { Son } & \text { Gebelikten } & \text { Sonra }\end{array}$} \\
\hline \multicolumn{8}{|c|}{ Geçen Süre } \\
\hline 2 yil ve daha az & 33 & 32,7 & 27 & 25,2 & 60 & 28,8 & $X^{2}=1,401$ \\
\hline 3 y1l ve daha fazla & 68 & 67,3 & 80 & 74,8 & 148 & 71,2 & $p=0,237$ \\
\hline \multicolumn{8}{|c|}{$\begin{array}{l}\text { Önceki Gebeliklerde Sorun } \\
\text { Yasama Durumu }\end{array}$} \\
\hline Var & 21 & 20,8 & 17 & 15,9 & 38 & 18,3 & $X^{2}=0,837$ \\
\hline Yok & 80 & 79,2 & 90 & 84,1 & 170 & 81,7 & $p=0,360$ \\
\hline
\end{tabular}

* Fisher exact test

** Multigravidler cevaplamıstır

***Düşük/Kürtajlar dahil edilmemiştir

Tablo 4. OGTT yaptırmayan gebelerin, testi yaptırmama nedenleri $(n=149)$

\begin{tabular}{lll}
\hline OGTT yaptırmama Nedenleri & Sayı & \% \\
\hline Bana ve bebeğime zararlı olduğu için & 32 & 21,5 \\
Gerekli olmadığını düşündüğ̈̈m için & 84 & 56,3 \\
Doktorum önermediği için & 26 & 17,4 \\
Testi yaptırma süresini geçtiğim için & 5 & 3,4 \\
Kan testi yaptırmaktan çekindiğim için & 2 & 1,4 \\
\hline TOPLAM & 149 & 100,0 \\
\hline
\end{tabular}


Çalışmada OGTT yaptırmayan gebelerin testi yaptırmama nedenleri sorgulandığında; ilk sırada "gerekli olmadığını düşünmelerinden kaynaklandığı", ikinci sirada "bebeğine ve kendine zarar verme ihtimali olduğu", üçüncü sırada ise "doktoru önermediği için yaptırmadığı" gerekçeleri sıralanmıştır. Literatürde yer alan çalışmalarda da görsel medyadan etkilenen gebelerin OGTT yaptırmama kararı aldıkları, ${ }^{1,21}$ yine bu testin kendilerine ve bebeklerine zarar vereceği endişesi taşıdıkları, 1,21,22,26 gerekli görmedikleri için yaptırmama kararı aldıklar1 ${ }^{26}$ bildirilmiştir. $\mathrm{Bu}$ sonuçlar bizim çalışma ile benzerlik göstermektedir. Yine bu sonuçlara baktığımızda gebelerin yaptırmalarını etkileyen önemli bir faktörün de sağlik profesyonelleri tarafindan yeterince bilgilendirilmedikleri ve yönlendirilmediklerinden kaynaklandı ğ 1 görülmüştür.

OGTT'ye karşı oluşan negatif tutumda görsel medyanın yanı sıra sağlık profesyonellerinin de bu konudaki tavrının gebelerin test yaptırma tutumlarını etkilediklerini göstermektedir. Oysaki GDM tanısı için kullanılan OGTT'nin oksidatif stresi artırdığına dair çalışmalar ${ }^{27,28}$ bulunsa da plasenta tarafindan oluşturulan biyolojik bariyer artan oksidatif stress ürünlerinin fetusa ulaşmasını engelleyerek oluşabilecek zararlı etkilere karşı fetüsü koruduğu bildirilmektedir. ${ }^{29}$

Dünya Sağlık Örgütü (World Health Organization-WHO), Amerikan Diyabet Derneği (ADA), Amerikan Jinekoloji ve Obstetri Kurulu (American College of Obstetricians and GynecologistsACOG), İngiltere Ulusal Sağlık ve Mükemmellik Enstitüsü (National Institute of Health and Clinical Exellence-NICE), TC. Sağlık Bakanlığı, Türk Jinekoloji ve Obstetri Derneği (TJOD) gibi birçok ulusal ve uluslararası sağlık kurum ve kuruluşları gebelikte GDM taramasinda OGTT'yi önermektedir. ${ }^{5,13,15-17,30}$

Gebelere bu testin öneminin başta ebeler olmak üzere tüm doğum öncesi bakım veren sağlik profesyonelleri tarafından bilgilendirme yapılması önemlidir. Koyucu ${ }^{21}$ çalışmasında gebelerin \%83'nün GDM ile ilgili yeterli seviye bilgi düzeylerinin olmadığını, Başbuğ ve ark. ${ }^{1}$ çalışmalarında ise, sağlık personelinin gebeleri yeterince bilgilendiremedikleri bildirilmiştir. Kutlu ve ark. $^{25}$ yaptığı çalışmada, katılımcıların \%48,1'inin tarama testlerini kadın doğum uzmanlarından öğrendiklerini, sağlık çalışanlarından tarama testleri hakkında bilgi edinme yüzdesinin hala istenen düzeyde olmadığ 1 bildirmiştir. Çalışmada da gebelerin beyanından ebelerin ve diğer sağlık profesyonellerinin benzer şekilde bilgilendirmedikleri anlaşılmaktadır.

Amerikan Diyabet Derneği (ADA) prekonsepsiyonel dönemden başlamak üzere gebelikte diyabet riskinin araştırılması gerektiğini ve tüm gebelerin OGTT ile taranmasını önermekte ve öneri düzeyini " $A$ " olarak bildirmektedir. ${ }^{5} \mathrm{Bu}$ kapsamda çalışmada yer alan ve OGTT yaptırmayan özellikle primigravid gebelerin diyabet açısından taranmaması maternal ve fetal ciddi sonuçlara yer açabilecektir. Yine çalışmada kan testi yaptırma süresini geçtiği ya da çekindiği için yaptırmayan gebelerin doğum öncesi izlem niteliği açısından da yetersizlik olduğunu düşündürmektedir. 'TC Sağl1k Bakanlığı Riskli Gebelik Yönetim Rehberi'nde tüm gebelere 24.-28. gebelik haftalarında OGTT testi yaptırılması önerilmektedir. ${ }^{17} \mathrm{Bu}$ gebelerin doğum öncesi bakım ve izleminde, sağlık profesyonellerinin OGTT konusunda yaptıkları bilgilendirmenin yetersiz olduğu düşünülmektedir.

\section{Sonuc}

$\mathrm{Bu}$ çalışma kapsamında, gebelerin sosyodemografik, sağlık ve obstetrik özelliklerinin OGTT yaptırma üzerine etki etmediği belirlenmiştir. OGTT yaptırmayan gebelerin, testin gerekli olmadığını, kendilerine ve bebeklerine zararlı olduğunu düşünmeleri veya doktorlarının önermemesi gibi sebeplerle testi yaptırmadıkları saptanmıştır. OGTT'ye ilişkin algıların OGTT yaptırma davranışına etkisinin olduğu görüldüğünden, sağlık profesyonellerinin bu algıda önemli rolü bulunduğu söylenebilir. Kadınların OGTT konusunda doğru bilgilendirilmesi önem arz etmektedir. 
Çalışmada elde edilen sonuçlar doğrultusunda; sağlik profesyonellerinin gebelere vermiş olduğu doğum öncesi bakımda OGTT testi hakkında etkin ve doğru bilgilendirme yapması, OGTT yaptırmak istemeyen gebelere çekincelerine ilişkin bilimsel ve kanıta dayalı bilgilendirmenin yapılması önerilmektedir. Ayrıca, gestasyonel diyabet riski olup, OGTT yaptırmayan gebelerle derinlemesine görüşme yöntemi ile araştırmalar yapılması ve test yaptırmama nedenlerinin niteliksel boyutta ele alınması önerilmektedir.

\section{Araştırmanın Etik Boyutu}

Araştırmanın yapılabilmesi için Etik kurul onayı alınmıştır (tarih: 10.10.2019; no: 71522473/050.01.04/85). Araştırma verilerinin toplanacağı kamu hastanesinden 16.09.2019 tarihinde yazılı izin alınmıştır. Ayrıca çalışma Helsinki Bildirgesi ilkelerine uygun olarak yürütülmüştür.

\section{Bilgilendirilmiş Onam}

Araştırmaya dahil edilen gebelere araştırmanın başında bilgi verilerek bilgilendirilmiş onamları alınmıştır.

\section{Yazar Katkıları}

Veri toplama, veri işleme, analizlerin yapılması ve yorumlanması Z.T. tarafindan yapılmıştır. Araştırmanın konsepti, dizaynı, literatür tarama ve makalenin yazımı Z.T. ve E.T. tarafından yapılmıştır.

\section{Çıkar Çatışması Beyanı}

$\mathrm{Bu}$ çalışmada yazarlar arasında çıkar çatışması bulunmamaktadır.

\section{Araştırma Desteği}

Araştırma için hiçbir kurumdan destek alınmamıştır.

\section{Kaynaklar}

1. Başbuğ A, Sönmez CI, Kaya AE, Yıldırım E. Gestasyonel diyabet taramasında karșılaşılan önemli bir problem: Gebeler neden oral glukoz tolerans testi yaptırmak istemiyor? Konuralp Tip Dergisi 2018; 10(2): 144- 8.

2. Committee on Practice Bulletins - Obstetrics. Practice bulletin no 137: Gestational diabetes mellitus. Obstet Gynecol 2013; 122: 406-16.

3. Guariguata L, Linnenkamp U, Beagley J, Whiting DR, Cho NH. Global estimates of the prevalence of hyperglyacemia in pregnancy. Diabetes Res Clin Pract 2014; 103: 176-85.

4. International Diabetes Federation (IDF), (2017) https://www.idf.org/our-activities/care-prevention/gdm (Erişim Tarihi: 22.01.2020)
5. American Diabetes Association (ADA). 2. Classification and diagnosis of diabetes: standards of medical care in diabetes. Diabetes care 2018; 41(Suppl 1): S13-S27.

6. Akgöl E, Abuşoğlu S, Gün FD, Ünlü A. Prevalence of gestational diabetes mellitus according to the different criterias. Turk J Obstet Gynecol 2017; 14(1): 18-22.

7. Balık G, Şahin Baydur S, Tekin Bayoğlu Y, Şentürk Ş, Kağıtcı M, Şahin Kır F. The prevalence of gestational diabetes mellitus in pregnants who applied to the maternity out patient clinic of a university hospital. Ege Journal of Medicine 2016; 55(2): 55-8.

8. Kaya R. Karaçam Z. Gestasyonel diyabet görülme sıklığı ve anne-bebek sağlı̆̆1 ile ilişkisi. Düzce Üniversitesi Sağllk Bilimleri Enstitüsü Dergisi 2019; 9(1): 10-18.

9. Horvath K, Koch K, Jeitler K, et al. Effects of treatment in women with gestational diabetes mellitus: Systematic review and meta-analysis. BMJ 2010; 340: c1395.

10. Metzger BE, Coustan DR, Trimble ER. Hyperglycemia and adverse pregnancy outcomes. Clinical Chemistry 2019; 65(7): 937-38.

11. Özkaya MO, Köse SA. Gestasyonel diyabet: Güncel durum. Perinatoloji Dergisi 2014; 22(2): 105-9.

12. Yaprak M, Gümüştakım RŞ, Tok A, Doğaner A. Gebelerde oral glukoz tolerans testi farkındalığının tespiti. Ankara Med J 2019 19(3): 635-47.

13. World Health Organization (WHO) Guideline Development Group (2013). Diagnostic criteria and classification of hyperglycaemia first detected in pregnancy. (WHO/NMH/MND Standard No. 13.2). Erişim: http://apps.who.int/iris/bitstream/

handle/10665/85975/who_nmh_mnd_13.2_eng.pdf?sequence= 1. (Erişim tarihi: 21.012020 ).

14. American Diabetes Association (ADA). Diabetes management guidelines. Diabetes Care 2015;38 (Suppl 1): S1-S93

15. The National Institute for Health and Care Excellence (NICE) Diabetes in pregnancy: Management of diabetes and its complications from preconception to postnatal period. 2015 Erişim: nice org.uk/guidance/ng3. (Erişim tarihi: 18.01 2020).

16. Türk Jinekolojik ve Obstetrik Derneği (TJOD). Gestasyonel Diyabet. 2014. Erişim: http://tjodistanbul.org/index. php?option=com_k2\&view=item\&id=401:gestasyoneldiyabet\&Itemid=830 (Erişim tarihi: 21.01 .2020 ).

17. Türkiye Cumhuriyeti (TC) Sağlık Bakanlığı Türkiye Halk Sağlığı Kurumu. Riskli gebelikler yönetim rehberi. 2014. Erişim:

https://sbu.saglik.gov.tr/Ekutuphane/kitaplar/risgebyonreh.pdf (Erişim tarihi: 11.01.2020)

18. Hocaoğlu M, Turgut A, Güzin K, ve ark. Why some pregnant women refuse glucose challenge test? Turkish pregnant women's perspectives for gestational diabetes mellitus screening. Northern Clinics of İstanbul 2019; 6(1): 7-12.

19. Landon MB, Spong CY, Thom E, et al. A multicenter, randomized trial of treatment for mild gestational diabetes. $N$ Engl J Med 2009; 361:1339-48.

20. Ulas SC. \& Durgun SK. Son trimester gebelerin antenatal dönemde yapılan rutin testler hakkındaki bilgi durumları ve uygulamalar1. 3rd International Science Symposium, Proceedıng Book,5-8 September 2018, Kosova ISS2018, Firat Akademi AŞ. 2018; 63-8.

21. Koyucu RG. Gestasyonel diyabet risk faktörleri çerçevesinde gebelerin glukoz tolerans testine ilişkin tutumları. Să̆lık ve Toplum 2018; 28(2): 65-72

22. Türkyılmaz E, Keleştemur E, Eray İK, Öcal FD, Avşar AFY. Knowledge level, attitude and behaviours about glucose challenge test among Turkish pregnant women. Ankara Med J 2016;16(2): 191-9.

23. Desdicioğlu R, Yıldırım M, Süleymanova İ, Atalay İ, Özcan M, Yavuz AF. Gebe kadınların antenatal testlere yaklaşımını etkileyen faktörler. Ankara Med J 2017;(1): 57-64.

24. Schwartz N, Green M.S, Yefet E, Nachum Z. Modifiable risk factors for gestational diabetes recurrence. Endocrine 2016; 54: 714-22.

25. Kutlu R, Uzun L, Karaoğlu N, Görkemli H. Awareness of pregnant women about routine applied screening tests and supportive treatments in a university hospital. Istanbul Medical Journal 2020; 21(1): 71-7.

26. Avci DK, Oner E. Examination of the knowledge, attitude and behaviours of pregnant women on screening tests made during pregnancy. East J Med 2018;23(2): 84-9. 
27. Mertoğlu C, Gunay M, Siranli G, Kulhan M, Gok G, Erel Ö. The effect of the $50 \mathrm{~g}$ glucose challenge test on the thiol/disulfide homeostasis in pregnancy. Fetal Pediatr Pathol 2018; 25: 1-10.

28. Nakanishi S, Yoneda M, Maeda S. Impact of glucose excursion and mean glucose concentration in oral glucose-tolerance test on oxidative stres among Japanese Americans. Diabetes, Metabolic Syndrome and Obesity: Targets and Therapy 2013; 6: 427-33. (doi:10.2147/DMSO.S53760).

29. Rueangdetnarong $\mathrm{H}$, Sekararithi $\mathrm{R}$, Jaiwongkam $\mathrm{T}$, et al. Comparisons of the oxidative stres biomarkers levels in gestational diabetes mellitus (GDM) andnon-GDM among Thai population: cohort study. Endocr Connect 2018; 7: 681-87.

30. The American College of Obstetricians and Gynecologists (ACOG). Gestational diabetes mellitus clinical management guidelines for obstetrician-gynecologists gestational diabetes mellitus, summary, Practice Bulletin 2018;131 (2, Summary): 406-8. 